\title{
Comparison of phonomyography, kinemyography and mechanomyography for neuromuscular monitoring
}

\author{
[Comparaison de la phonomyographie, la cinémyographie et la mécanomyo- \\ graphie pour le monitorage neuromusculaire] \\ Guillaume Trager MSc, Guillaume Michaud, Stéphane Deschamps MSc, Thomas M. Hemmerling MD DEAA
}

Purpose: The gold standard of neuromuscular monitoring is mechanomyography (MMG). Phonomyography (PMG) and kinemyography (KMG) are new methods of neuromuscular monitoring. In this study, all three methods were compared to determine neuromuscular blockade at the adductor pollicis muscle.

Methods: In 14 patients, phonomyography was recorded via a microphone taped to the thenar region. A standard mechanomyographic device was applied to the same thumb, and attached to the force transducer. On the contralateral side, a NMT-Mechanosensor ${ }^{\circledR}$ probe was attached to the thumb and forefinger (KMG). After induction of general anaesthesia, the ulnar nerves were stimulated supramaximally using superficial electrodes at the wrists using train-of-four (TOF) stimulation every $12 \mathrm{sec}$. Onset and recovery indices measured by the three methods after mivacurium $0.2 \mathrm{mg} \cdot \mathrm{kg}^{-1}$ iv were compared using ANOVA-multiple group comparisons. Agreement between methods was determined using Lin's concordance correlation coefficient.

Results: Onset time and peak effect measured via MMG and PMG were similar. Recovery times from neuromuscular blockade (NMB) as measured via the three methods were not different. Agreement between PMG and MMG was excellent for onset and offset of NMB but unsatisfactory for peak effect. Agreement between MMG and KMG was satisfactory for TOF 0.25 and 0.50 , and excellent for TOF 0.75 and 0.90 (onset and peak effect not determined for KMG). Agreement between PMG and KMG was satisfactory for TOF $0.25,0.50$ and 0.75 , and excellent for TOF 0.90 .

Conclusion: Mechanomyography, PMG and KMG show satisfactory agreement for determination of recovery of NMB for clinical purposes.
Objectif: La référence en monitorage neuromusculaire est la mécanomyographie (MMG). La phonomyographie (PMG) et la cinémyographie (CMG) sont de nouvelles méthodes. Nous comparons les trois méthodes pour qualifier le blocage neuromusculaire à l'adducteur du pouce.

Méthode : La phonomyographie a été enregistrée par un microphone fixé à la région thénar chez 14 patients. Un appareil de mécanographie standard, au même pouce, a été fixé au transducteur de force. Au côté opposé, une sonde de NMTMechanosensor ${ }^{\circledR}$ a été fixée au pouce et à l'index (CMG). Après l'induction de l'anesthésie, les nerfs cubitaux ont reçu une stimulation supramaximale, utilisant un train-de-quatre (TDQ) toutes les $12 \mathrm{sec}$, produite par des électrodes superficielles aux poignets. Les indices du début et de la fin du bloc, mesurés par les trois méthodes après l'administration iv de $0,2 \mathrm{mg} \cdot \mathrm{kg}^{-1}$ de mivacurium, ont été comparés par une analyse ANOVA de groupes multiples. La concordance entre les méthodes a été déterminée par le coefficient de concordance et de corrélation de Lin.

Résultats : Les temps du début et de l'effet maximal du blocage neuromusculaire (BNM) étaient similaires par MMG et PMG. Les temps de récupération du BNM ont été similaires avec les trois méthodes. La concordance entre la PMG et la MMG a été excellente pour le début et la fin du BNM, mais insatisfaisante pour l'effet maximal. La concordance entre la MMG et la CMG a été satisfaisante pour les TDQ 0,25 et 0,50, et excellente pour les $T D Q$ 0,75 et 0,90 (début et effet maximal non déterminés pour le CMG). La concordance entre la PMG et la CMG a été satisfaisante pour les TDQ 0,25, 0,50 et 0,75 et excellente pour le TDQ 0,90.

Conclusion : La MMG, la PMG et la CMG affichent une concordance satisfaisante pour la détermination de la récupération après un BNM réalisé pour des objectifs cliniques.

From the Neuromuscular Research Group (NRG), Department of Anesthesiology, Centre Hospitalier de l'Université de Montréal (CHUM) Hôtel-Dieu, Université de Montréal, Montréal, Québec, Canada.

Address correspondence to: Dr. Thomas M. Hemmerling, Department of Anesthesiology, Université de Montréal, Hôtel-Dieu, 3840 Rue St. Urbain, Montréal, Québec H2W 1T8, Canada. Phone: 514-890-8000 ext. 14570; Fax: 514-412-7222; E-mail:

thomashemmerling@hotmail.com

This work was performed using departmental internal funds. In addition, Dr. Hemmerling is recipient of the 2003 Career Scientist Award of the Canadian Anesthesiologists' Society.

Accepted for publication August 10, 2005.

Revision accepted August 29, 2005. 
M ECHANOMYOGRAPHY (MMG) has long been regarded as the gold standard of neuromuscular monitoring in that it measures the actual force created by muscle contraction. However, it has limitations, notably the difficult set-up procedures with special arm boards, and requirement for stable positioning of the arm and bulky force transducers. Furthermore, it cannot be used at muscles other than the adductor pollicis, such as the corrugator supercilii or the orbicularis oculi.

Kinemyography (KMG) has been available for some years in form of the NMT-Mechanosensor ${ }^{\circledR}$ integrated in the Datex anesthetic machine (NMT-Mechanosensor, Datex Instrumentations Inc., Madison, WI, USA). It consists of a moulded plastic device which can be applied into the groove of the thumb and forefinger by use of adhesive tape. In addition, as known for other methods such as acceleromyography, ${ }^{1}$ attachment of the arm to an arm board may increase the precision of measurement. The manufacturer states that the method is based upon the detection of bending and deformation of a piezo-electric sensor wafer strip by movement of the thumb, caused by contraction of the adductor pollicis muscle. Some studies have shown that its agreement with MMG for scientific purposes might be limited with unacceptably wide limits of agreement; ${ }^{2}$ in clinical circumstances it can be used reasonably well to detect time to tracheal intubation and recovery of neuromuscular block (NMB) ${ }^{2,3}$ However, the device can only be applied to measure NMB at the adductor pollicis muscle and there is only one size of the moulded probe.

Phonomyography (PMG) has been described as a new method of neuromuscular monitoring. ${ }^{4}$ The method is based upon the fact that muscle contraction evokes low frequency sounds, which can be recorded using special microphones ${ }^{5,6}$. Initially, this method was called acoustic myography and used an air-chamber interface between the skin and the microphone. ${ }^{7,8}$ It shows good agreement for several muscles with the gold standard of monitoring, MMG, ${ }^{9-11}$ and can be applied at any muscle of interest.

The purpose of this study was to compare and determine the agreement of $\mathrm{PMG}, \mathrm{KMG}$, and $\mathrm{MMG}$, for detection of NMB after a dose of mivacurium $0.2 \mathrm{mg} \cdot \mathrm{kg}^{-1}$ during train-of-four (TOF) stimulation.

\section{Methods}

After approval of the local Ethics Committee and obtaining informed consent, 14 patients undergoing general surgery were included in the study. Patients with coexisting neuromuscular disease or patients on medication known to interact with neuromuscular transmission, or presenting atypical pseudocholinesterase, were excluded.
After arrival in the operating theatre, routine monitoring (non-invasive blood pressure, pulse oximetry, five-lead electrocardiography) was applied. Anesthesia was induced with remifentanil 0.25 to $0.5 \mu \mathrm{g} \cdot \mathrm{kg}^{-1} \cdot \mathrm{min}^{-1} i v$; two minutes later, propofol 2 to $3 \mathrm{mg} \cdot \mathrm{kg}^{-1} i v$ was injected. After loss of consciousness and ventilation via facemask for two minutes with $100 \%$ oxygen, a laryngeal mask airway (LMA; size: 4 for women, size 5 for men, LMA company, Wooburn Green, UK) was inserted and controlled ventilation commenced with minute ventilation set to maintain a $\mathrm{P}_{\mathrm{ETCO} 2}$ of 35 to $45 \mathrm{mmHg}$. Anesthesia was maintained with sevoflurane $2-3 \%$ end-tidal in a mixture of $30 \%$ oxygen and medical air, to maintain a bispectral index of 50 (BIS; A-2000 monitoring system, Aspect Medical Company, USA). Analgesia was provided by remifentanil 0.05 to $0.25 \mu \mathrm{g} \cdot \mathrm{kg}^{-1} \cdot \mathrm{min}^{-1}$ throughout surgery. In each patient, the force of contraction of the adductor pollicis was measured using a force transducer (Grass FT-10, Grass Instruments Co., Quincy, MA, USA; preload: 300 $\mathrm{mg}$ ). A specially molded cast was used to stabilize the arm in position. On the same hand, a piezoelectric microphone (diameter: $1.6 \mathrm{~cm}$, Model 1010, Grass Instruments, AstroMed, Inc., West Warwick, IL, USA; frequency response: 2.5 to $5 \mathrm{kHz}$, signal output: $20-40 \mathrm{mV}$ into $1 \mathrm{M} \Omega$ ) was attached to the thenar region to record the acoustic signals (Figure 1). The microphone signal was amplified and band pass filtered between 0.5 and $1000 \mathrm{~Hz}$ using an AC/DC amplifier (Model 7P122, Grass Instruments, Astra-Med, Inc., West Warwick, IL, USA). The signals were sampled continuously at $100 \mathrm{~Hz}$ using the Polyview ${ }^{\circledR}$ software package (Astra-Med, Inc., West Warwick, IL, USA), digitized and stored on a portable microcomputer. The single twitch phonomyographic signal was measured peak-topeak. On the other arm, NMB was measured by KMG by applying the KMG-probe to the hand (Datex, NMTMechanosensor, Datex Instrumentation) and the digits III to $\mathrm{V}$ taped to an armboard in routine fashion (Figure 2). Hand temperature was measured using standard temperature probes at both hands.

In all patients, the ulnar nerves were stimulated at the forearms with TOF twitches via surface electrodes using two constant current stimulators (Innervator ${ }^{\circledR}$, Fisher and Paykel Healthcare, Auckland, New Zealand) which generated single-twitch square pulses of $0.2 \mathrm{msec}$ with a current intensity between 0 and $70 \mathrm{~mA}$ (TOF stimulation every $12 \mathrm{sec}$ ). Supramaximal stimulation was determined using single twitch stimulation at $0.1 \mathrm{~Hz}$. After at least five minutes of supramaximal stimulation and stable baselines for both recordings, mivacurium $0.2 \mathrm{mg} \cdot \mathrm{kg}^{-1}$ was injected within five seconds into a fast flowing solution of Ringer's lactate. Onset, maximum effect and offset of neuromuscular blockade after mivacurium 0.2 $\mathrm{mg} \cdot \mathrm{kg}^{-1}$ were determined. 


\begin{tabular}{llll}
\hline & $\begin{array}{l}\text { Phonomyography } \\
\text { mean }(\mathrm{SD})\end{array}$ & $\begin{array}{l}\text { Mechanomyography } \\
\text { mean }(\mathrm{SD})\end{array}$ & $\begin{array}{l}\text { Kinemyography } \\
\text { mean }(\mathrm{SD})\end{array}$ \\
\hline Onset $(\mathrm{sec})$ & $217(66)$ & $216(70)$ & N/A \\
Peak effect $(\%)$ & $97(3)$ & $96(4)$ & N/A \\
TOF 0.25 $(\mathrm{min})$ & $28(6)$ & $29(7)$ & $29(6)$ \\
TOF 0.50 $(\mathrm{min})$ & $31(9)$ & $32(8)$ & $35(8)$ \\
TOF 0.75 (min) & $40(12)$ & $37(11)$ & $43(11)$ \\
TOF 0.90 (min) & $51(14)$ & $53(14)$ & $53(13)$ \\
\hline
\end{tabular}

$\mathrm{N} / \mathrm{A}=$ not available; $\mathrm{TOF}=$ train-of-four; $\mathrm{SD}=$ standard deviation. Results are presented as mean \pm SD. All times were not significantly different between the three methods. Onset time: time to reach peak effect. Peak effect: maximum decrease in twitch height (Tl) in comparison to control twitch height. TOF $0.25=$ time to reach a TOF ratio of T4 to Tl of $25 \%$. TOF $0.50=$ time to reach a TOF ratio of T4 to $\mathrm{Tl}$ of $50 \%$. TOF 0.75 = time to reach a TOF ratio of $\mathrm{T} 4$ to $\mathrm{Tl}$ of $75 \%$. TOF $0.90=$ time to reach a $\mathrm{TOF}$ ratio of $\mathrm{T} 4$ to $\mathrm{Tl}$ of $90 \%$.

TABLE IIA

\begin{tabular}{llll}
\hline & $\begin{array}{l}P M G \text { vs } M M G \\
\alpha_{c} \text { lower one-sided 95\% CL) }\end{array}$ & $\begin{array}{l}P M G \text { vs } K M G \\
\alpha_{c} \text { (lower one-sided 95\% CL) }\end{array}$ & $\begin{array}{l}\text { MMG vs } K M G \\
\alpha_{c} \text { (lower one-sided 95\% CL) }\end{array}$ \\
\hline TOF 0.25 & $0.9768(0.9484)$ & $0.7561(0.5476)$ & $0.8198(0.6781)$ \\
TOF 0.50 & $0.9509(0.9119)$ & $0.857(0.7455)$ & $0.8604(0.7333)$ \\
TOF 0.75 & $0.9789(0.9604)$ & $0.881(0.7794)$ & $0.9042(0.8159)$ \\
TOF 0.90 & $0.964(0.9310)$ & $0.9493(0.9051)$ & $0.9249(0.8573)$ \\
Onset & $0.9396(0.8849)$ & & \\
Peak effect & $0.4155(0.0399)$ & & \\
\hline
\end{tabular}

PMG = phonomyography; $\mathrm{MMG}=$ mechanomyography; $\mathrm{KMG}=$ kinemyography. $\mathrm{CL}=$ confidence limits. TOF $=$ train-of-four. Note: concordance correlation coefficient $\left(\alpha_{c}\right)(\operatorname{Lin}) \cdot \mathrm{p}_{\mathrm{c}}=$ Description for strength of agreement: $<0.6=$ unsatisfactory; 0.6 to $0.9=$ satisfactory; 0.91 to $\mathrm{l}=$ excellent.

TABLE IIB

\begin{tabular}{|c|c|c|c|}
\hline & $\begin{array}{l}M M G-P M G \\
\text { Bias (precision }=S D \text { of mean of difference) }\end{array}$ & $\begin{array}{l}P M G-K M G \\
\text { Bias (precision }=S D \text { of mean of difference) }\end{array}$ & $\begin{array}{l}K M G-M M G \\
\text { Bias (precision }=S D \text { of mean of difference) }\end{array}$ \\
\hline Onset (s) & $-5(16)$ & N/A & N/A \\
\hline Peak effect (\%) & $-0.7(3.2)$ & N/A & N/A \\
\hline TOF $0.25(\mathrm{~min})$ & $0.2(2.1)$ & $2.6(3)$ & $2.4(4.2)$ \\
\hline TOF 0.50 (min) & $0.3(2.6)$ & $-0.7(4.2)$ & $-0.9(4.5)$ \\
\hline TOF 0.75 (min) & $1.2(2.0)$ & $1.5(5.5)$ & $0.3(5.6)$ \\
\hline TOF $0.90(\mathrm{~min})$ & $1.4(3.1)$ & $2.0(3.5)$ & $0.6(4.7)$ \\
\hline
\end{tabular}

The first twitch response was used to analyze onset time (time to reach maximum decrease of twitch response) and the peak effect was determined as the maximum decrease of the twitch response using MMG and PMG. Times to reach a TOF ratio of 0.25 , $0.5,0.75$, and 0.9 were calculated for MMG, KMG and PMG simultaneously.

Sample size was calculated based on TOF 0.8 findings for $\mathrm{KMG}$ and $\mathrm{MMG}$ in a previous study, for a power of 0.8 and $\alpha=0.05 .^{3}$ Data were compared between all methods using an ANOVA for multiple comparisons, $P$ $<0.05$ was considered significant (SPSS software, SPSS
Inc., Chicago, IL, USA). Lin's concordance correlation coefficient $\left(\alpha_{c}\right)$ was determined at all time periods for two methods each ${ }^{12}$ and presented with the lower onesided $95 \%$ confidence limit (GenSTAT software, VSN International Ltd., Herts, UK). Agreement between two methods was assessed using the concordance correlation coefficient using the following degrees: $\alpha_{c}<0.6,0.6$ to 0.9 , and 0.91 to 1 were considered as unsatisfactory, satisfactory and excellent agreement, respectively. ${ }^{13}$ Bias as the mean of the differences and precision as standard deviation of the mean were also determined for all pharmacodynamic times. 


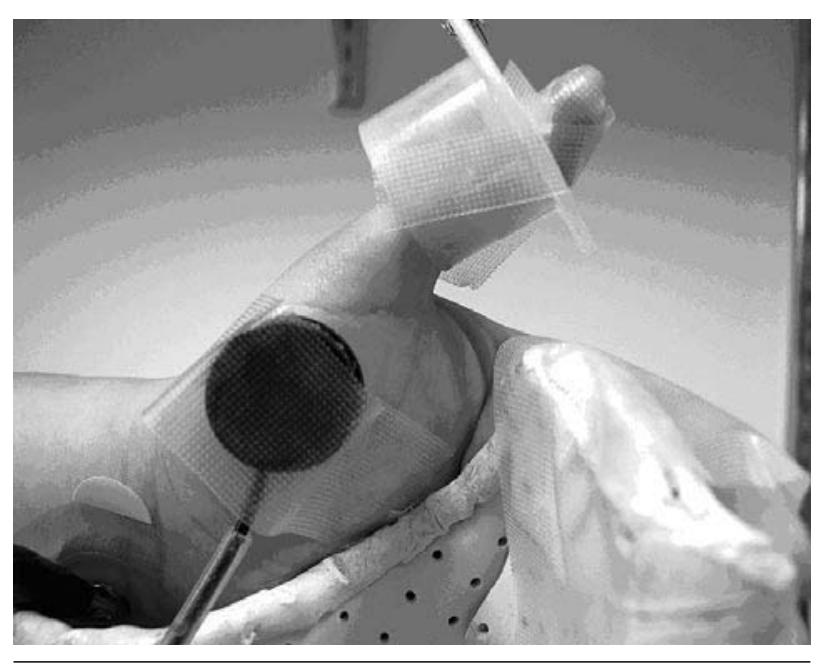

FIGURE 1 Location of force transducer (including the moulded mechanomyographic cast device) and the microphone.

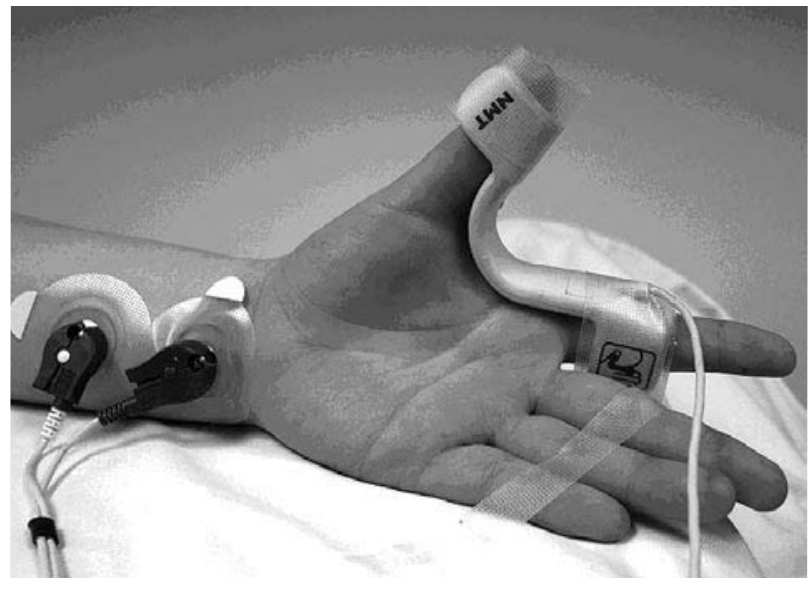

FIGURE 2 Application of Mechanosensor device at the thumb. Index and thumb are free to move and the other three fingers are attached to the arm board using an adhesive tape in order to limit signal perturbation.

\section{Results}

In all 14 patients (six women, eight men, mean age $39 \pm 17 \mathrm{yr}$, mean weight of $81 \pm 13 \mathrm{~kg}$ ), pharmacodynamic results with both methods could be obtained. Recordings of signals were continued until TOF ratios were greater than 0.9 in all patients. Hand temperature was above $35.5^{\circ} \mathrm{C}$ in all patients.

Onset times and peak effect measured via MMG and PMG were similar. Offset of NMB as measured via the three methods was not statistically significant (Table I). Agreement between PMG and MMG was excellent for onset and offset of NMB, while unsatisfactory for peak effect. Agreement between MMG and KMG was satisfactory for TOF 0.25 and 0.50 , excellent for TOF 0.75 and 0.90 (onset and peak effect not determined for KMG). Agreement between PMG and KMG was satisfactory for TOF $0.25,0.50$ and 0.75 , excellent for TOF 0.90 (Table II).

\section{Discussion}

Throughout, excellent agreement for assessment of onset time and TOF-recovery was only found between MMG and PMG; at least satisfactory agreement for determination of TOF-recovery was found between all methods. Whereas in determination of peak effect using either MMG or PMG, there was unsatisfactory agreement, though with minimal bias and clinically acceptable precision.

We did not determine onset time and peak effect using KMG because the module integrated in the Datex anesthetic machine does not allow simultaneous

measurement of single twitch amplitudes in real time; in our setting, it only gives the TOF-ratio (Figure 3).

So far, there are few studies which compared KMG with other methods for neuromuscular monitoring. Dahaba et al. ${ }^{3}$ compared KMG and MMG for monitoring $\mathrm{NMB}$ in 20 patients after rocuronium 0.6 $\mathrm{mg} \cdot \mathrm{kg}^{-1}$. They found that although both methods showed good agreement to determine recovery to TOF-ratio of 0.8 , KMG lagged behind in determining the full course of recovery. However, Dahaba et al. ${ }^{3}$ did not determine the course of recovery by using different TOF-ratios, but recovery to different levels of first twitch heights. This might highlight differences between the two methods more than when recovery is determined by using different TOF-ratios as done in the current study - and in clinical practice. This theory is supported by the results of another study by Motamed et al. ${ }^{2}$ which showed good agreement between KMG and MMG for determining TOF-ratios between 0.1 to 0.95 during recovery of NMB. Our results confirm results by Motamed; KMG is reasonably precise for a routine clinical monitoring whenever TOF-ratios during surgical relaxation or recovery of NMB are measured.

Various studies have confirmed good agreement between PMG and MMG (or MMG-alike methods) for several muscles. This is the first study to compare MMG with KMG demonstrating good agreement for determination of TOF-ratios during recovery from NMB. This means that for routine clinical use, 

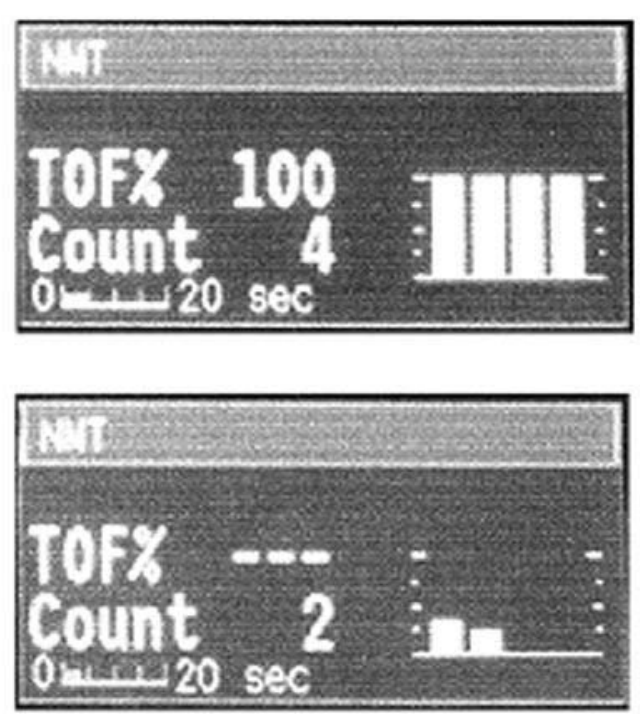

FIGURE 3 Kinemyography - display in train-of-four (TOF) mode. The screen presents the TOF-ratio percentage and TOF count. On the right part, the display bars represent the amplitude of each twitch. If there is no fourth twitch, it only gives the number of twitches, but not the signal height of the first twitch.

both monitoring methods can be used, and agree well with MMG; they are both easier to apply than MMG. In contrast to the study of Motamed et al., ${ }^{2}$ we attached the hand to the arm board even with the Mechanosensor. It is not clear whether this has an influence on the results, although Motamed et al. ${ }^{2}$ argue that it is not necessary to immobilize the hand, since the piezo-electric device only detects movement between the index finger and the thumb. There is no study confirming this theory. From a practical standpoint, stimulation of the ulnar nerve can produce movements of the hand and misplace the hand on an arm board, thus limiting the free movement of the thumb; this might alter the measurements. Therefore additional immobilization via adhesive tape was made to ensure free and repetitive movement of the thumb and index finger (Figure 2).

The standard module used for this study does not include the possibility of simultaneously measuring the first twitch heights and TOF-ratios. Therefore, we can only present TOF ratio measurement. When the movement caused by the fourth stimulation of the TOF is not detectable, the Datex mechanosensor module no longer displays a TOF-ratio, but only the number of twitches detected (Figure 3). That is why we are not able to present onset time and peak effect for the KMG method (an optional software to analyze first twitch signal heights was not available). However, since the purpose of this study was comparison of the three methods for clinical purposes, we assume that TOF-ratios will generally be used, especially to determine complete recovery from NMB.

This study shows that PMG demonstrates a very good concordance in the recovery period with a commercial monitoring system (M-NMT). In comparison to MMG and KMG, it can be applied to all muscles of interest. The possibility of monitoring the corrugator supercilii muscle is of interest to the clinician.

Determination of agreement between the three methods, in pairs, was performed by using Lin's correlation coefficient, a relatively new statistical method. ${ }^{12}$ Lin's correlation coefficient evaluates the agreement between two paired measures, and the description is based on the expected value of the squared distance function. It provides an assessment of agreement between alternative methods of continuous data collection, and it appears to avoid shortcomings associated with the usual procedures (e.g., Pearson's correlation coefficient, paired t test or least squares analysis of slope and intercept). The test is robust on as few as ten pairs of data. As with the Bland Altman test, an alternative and more widely used test of agreement between two monitoring methods ${ }^{14}$ calculation of agreement is simple and precise. To date, however, there are no uniform classifications of the strength of the Lin agreement. Our criteria represent one of the more commonly found classifications. A difficulty of interpreting Lin's coefficient is highlighted by the unsatisfactory strength of agreement for the peak effect when determined using PMG and MMG. However, the two monitoring methods demonstrate a minimal bias of $-0.7 \%$ with a precision of $3 \%$. Careful clinical interpretation of the Lin coefficient, together with presentation of bias and precision are the basis of meaningful comparison of two monitoring methods.

In summary, for determination of onset and TOFrecovery, MMG and PMG show satisfactory agreement for clinical purposes. These monitoring modalities can be used interchangeably to determine TOF- recovery of NMB in the clinical setting.

\section{References}

1 Dubois PE, Gourdin M, Russell K, Jamart J. Installation of the hand influences acceleromyography measurement. A comparison with mechanomyography during neuromuscular recovery. Acta Anaesthesiol Belg 2005; 56: $163-6$. 
2 Motamed C, Kirov K, Combes X, Duvaldestin P. Comparison between the Datex-Ohmeda M-NMT module and a force-displacement transducer for monitoring neuromuscular blockade. Eur J Anaesthesiol 2003; 20: 467-9.

3 Dahaba AA, von Klobucar F, Rehak PH, List WF. The neuromuscular transmission module versus the relaxometer mechanomyograph for neuromuscular block monitoring. Anesth Analg 2002; 94: 591-6.

4 Hemmerling TM, Donati F, Beaulieu P, Babin D. Phonomyography of the corrugator supercilii muscle: signal characteristics, best recording site and comparison with acceleromyography. Br J Anaesth 2002; 88: 389-93.

5 Barry DT, Geiringer SR, Ball RD. Acoustic myography: a noninvasive monitor of motor unit fatigue. Muscle Nerve 1985; 8: 189-94.

6 Barry DT. Acoustic signals from frog skeletal muscle. Biophys J 1987; 51: 769-73.

7 Bellemare F, Couture J, Donati F, Pland B. Temporal relation between acoustic and force responses at the adductor pollicis during nondepolarizing neuromuscular block. Anesthesiology 2000; 93: 646-52.

8 Dascalu A, Geller E, Moalem Y, Manoah M, Enav S, $R$ udick $Z$. Acoustic monitoring of intraoperative neuromuscular block. Br J Anaesth 1999; 83: 405-9.

9 Hemmerling TM, Michand G, Trager G, Deschamps S, Babin D, Donati F. Phonomyography and mechanomyography can be used interchangeably to measure neuromuscular block at the adductor pollicis muscle. Anesth Analg 2004; 98: 377-81.

10 Hemmerling TM, Babin D, Donati F. Phonomyography as a novel method to determine neuromuscular blockade at the laryngeal adductor muscles: comparison with the cuff pressure method. Anesthesiology 2003; 98: 359-63.

11 Hemmerling TM, Michand G, Babin D, Trager G, Donati F. Comparison of phonomyography with balloon pressure mechanomyography to measure contractile force at the corrugator supercilii muscle. Can J Anesth 2004; 51: 116-21.

12 Lin L, Torbeck LD. Coefficient of accuracy and concordance correlation coefficient: new statistics for methods comparison. PDA J Pharm Sci Technol 1998; 52: 55-9.

13 Warke TJ, Kamath S, Fitch PS, Brown V, Shields MD, Ennis $M$. The repeatability of nonbronchoscopic bronchoalveolar lavage differential cell counts. Eur Respir J 2001; 18: 1009-12.

14 Bland JM, Altman DG. Statistical methods for assessing agreement between two methods of clinical measurement. Lancet 1986; 1: 307-10. 